\title{
CARÊNCIA HABITACIONAL E DÉFICIT DE MORADIAS questões metodológicas
}

\author{
Marie Louise Bulhões Pedreira Genevois \\ Assistente Social, Analista da Fundação Seade \\ Olavo Viana Costa \\ Sociólogo, Analista da Fundação Seade
}

\begin{abstract}
Resumo: Com o objetivo de aprimorar as estimativas sobre o déficit habitacional no país, este artigo compara a metodologia adotada pela Fundação Seade, em 2000, para atender uma demanda da Assembléia Legislativa do Estado de São Paulo, com aquela desenvolvida originariamente pela Fundação João Pinheiro, órgão oficial de estatística do Governo do Estado de Minas Gerais, que deu origem ao livro Déficit habitacional no Brasil, publicado em 1995.

Palavras-chave: política habitacional; déficit habitacional; pesquisas de domicílios.
\end{abstract}

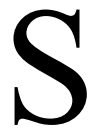

egundo dados oficiais, mais da metade dos paulistanos $(52 \%)$ vive em favelas, cortiços e loteamentos clandestinos (O Estado de S.Paulo, 10/12/00). Os dois primeiros tipos de moradia são tradicionalmente considerados precários. A ocupação desordenada do solo urbano, nos chamados loteamentos clandestinos, resulta em áreas sem infra-estrutura adequada, com falta de áreas verdes e grande concentração de moradias, que transformam bairros inteiros em locais impróprios para morar. Outras situações também demandam políticas habitacionais: algumas são facilmente observáveis, como a dos chamados "moradores de rua"; outras são menos visíveis, como casas e apartamentos congestionados ou sem condições de conservação para garantir a saúde de seus ocupantes.

Para enfrentar as carências é indispensável uma abordagem coletiva da questão habitacional urbana - não é possível simplesmente atribuir aos cidadãos que ocupam a "cidade irregular" a responsabilidade por esta situação, uma vez que, sem acesso ao mercado imobiliário formal, buscam alternativas para garantir um abrigo nem sempre em conformidade com as normas legais. É preciso levar em conta tanto as condições da unidade habitacional quanto do conjunto urbano, sabendo que, muitas vezes, as situações irregulares de alguns domicílios são camufladas pelos próprios moradores, com o intuito de preservar seu abrigo. E para estabelecer prio- ridades é preciso identificar as situações em que programas alternativos à construção de novas moradias podem garantir um abrigo digno.

Nesse sentido, o debate metodológico é fundamental para o aprimoramento dos estudos e pesquisas sobre carência habitacional no Brasil, até pela diversidade de metodologias, que resulta em estimativas desencontradas sobre o déficit de moradias no país. De fato, os dados estatísticos disponíveis sobre o tema, divulgados por fontes diversas, são discrepantes, o que impossibilita a comparação entre diferentes momentos em uma mesma região ou entre diferentes regiões. Exemplo dos mais eloqüentes é a projeção da população que mora em cortiços no município de São Paulo, cuja proporção, dependendo da fonte consultada, varia entre $8 \%$ e $39 \%$ da população total (CDHU, 1988:5).

O simples registro das discrepâncias entre as estimativas oficiais é insuficiente para aprimorar o diagnóstico sobre a situação habitacional no Brasil - sobretudo para a definição de políticas públicas para o setor. Não basta reconhecer que os conceitos e os procedimentos adotados nos diferentes levantamentos de campo determinam os resultados obtidos pelas pesquisas em habitação - quaisquer que sejam elas. É preciso explicitar e aprimorar tais conceitos, bem como seus respectivos indicadores, para captar as várias modalidades de carência habitacional no país - difíceis de serem identificadas, quando se conside- 
ra a cidade real e não a legal - e possibilitar ações capazes de suprimi-las. Reciprocamente, tal aprimoramento só pode acontecer com a explicitação dos procedimentos de pesquisa e suas justificativas, sem receio de se declarar os limites das diferentes metodologias adotadas.

Visando contribuir para o aprimoramento das estimativas sobre o déficit habitacional no Brasil, este artigo compara a metodologia utilizada pela Fundação Seade, em 2000, para atender a uma demanda da Assembléia Legislativa do Estado de São Paulo, com aquela divulgada pela Fundação João Pinheiro, ${ }^{1}$ em 1995 , no livro Déficit habitacional no Brasil. Não se busca uma definição de qual metodologia é a melhor, pois as duas se baseiam em fontes de dados diferentes e, portanto, adotam conceitos, definições operacionais e indicadores diversos para os vários componentes do déficit habitacional. Assim, é possível, fundamentalmente, tornar claras suas diferenças e a avaliação de seu potencial e de suas limitações como estratégias de pesquisa que permitem subsidiar o planejamento e a tomada de decisões governamentais na área da habitação.

\section{FONTE DE DADOS}

A Fundação Seade calculou o déficit habitacional no Estado de São Paulo para subsidiar o Fórum São Paulo Século XXI, recentemente instituído pela Assembléia Legislativa com a finalidade de mobilizar a sociedade paulista para a discussão de temas e problemas relevantes para o seu futuro. Tal demanda somente pôde ser atendida em razão da disponibilidade de informações estatísticas apropriadas para esse fim, provenientes da Pesquisa de Condições de Vida - PCV. Trata-se de um levantamento por amostragem de domicílios, realizado de quatro em quatro anos, que propicia uma acurada análise das condições de vida da população, tomando por base características de moradia, instrução, emprego, renda e utilização de serviços de saúde.

Ainda que o levantamento da PCV sobre moradia não esteja voltado exclusivamente para a mensuração do déficit habitacional, presta-se a essa finalidade específica porque o questionário adotado permite a definição operacional de um padrão mínimo de habitabilidade, a partir do qual torna-se possível a classificação de toda e qualquer unidade habitacional conforme características de edificação, de espaço interno e de sua utilização pelos ocupantes. Por essa classificação, que se baseia na verificação de um conjunto de atributos ordenados hierarqui- camente, consideram-se precárias as moradias construídas com material impróprio (barracos), as que estão localizadas em loteamento não-planejado (favelas) e as que obrigam seus ocupantes a dividir equipamentos e instalações sanitárias indispensáveis, como cozinha, banheiro e tanque de lavar roupas (cortiços). Uma vez que não satisfazem requisitos mínimos de habitabilidade, tais unidades habitacionais não são estudadas quanto ao espaço interno e à densidade, atributos considerados para diferenciar os demais tipos de moradia: as construídas com material apropriado para garantir solidez e segurança a seus ocupantes, que estão inseridas em áreas onde as vias de acesso e a separação entre os domicílios foram planejadas conforme as normas urbanas de ocupação e que dispõem de equipamentos e instalações sanitárias de uso privativo de seus ocupantes.

Para avaliar a relação entre o espaço interno da moradia e sua utilização pelos ocupantes, a PCV utilizou dois indicadores: "número e tipos de cômodos existentes" e "cômodos utilizados para dormir". O primeiro estabelece como adequada a composição mínima de quarto, sala, cozinha e banheiro, o que se justifica pelo princípio de que a execução das funções básicas de toda e qualquer moradia - repouso, estar, preparação de alimentos e higiene exige os quatro compartimentos para evitar superposição de funções, independente do número de ocupantes. ${ }^{2} \mathrm{O}$ segundo estabelece como adequada a utilização exclusiva dos quartos como dormitórios, e se justifica pelo princípio de que falta espaço numa moradia onde a sala ou a cozinha também servem para um ou mais moradores dormirem regularmente.

Assim, a PCV considera que dispor dos quatro cômodos básicos e de quartos em quantidade suficiente para o repouso de todos os moradores corresponde ao espaço mínimo adequado. As casas e os apartamentos que não apresentam tais requisitos foram classificados como insatisfatórios na escala de condições habitacionais. Os demais domicílios, que dispõem das características indispensáveis de adequação, foram divididos em satisfatórios quando só os quartos são usados como dormitórios - $\mathrm{e}$ mais que satisfatórios - quando sobram quartos.

Importa lembrar que a PCV levantou outras informações sobre condições habitacionais, além daquelas que entraram na escala classificatória. O levantamento sobre a infra-estrutura urbana disponível, por exemplo, inclui os equipamentos na rua de acesso (iluminação pública, pavimentação, guias e sarjetas) e os serviços internos ao domicílio (ligações com as redes públicas de abastecimento 
de energia elétrica e de água, bem como de coleta de lixo e de esgotamento sanitário e, na ausência dessas ligações, as alternativas adotadas).

No vínculo da família com sua habitação, a PCV identificou quatro situações: propriedade, aluguel, cessão e invasão. Note-se que a moradia invadida corresponde à condição das famílias que moram em situação irregular, incluindo as que invadiram o domicílio e aquelas que ocuparam o terreno e construíram suas casas. Sabendo-se, por pesquisas anteriores, que metade da população vive em moradia própria - incluindo nessa categoria todo e qualquer tipo de habitação, independentemente de já estar quitada ou não e da sua adequação física -, parte das questões dirigiu-se aos moradores proprietários, a fim de produzir indicadores sobre as formas de aquisição e sobre os arranjos adotados por essas famílias para garantir o seu abrigo.

\section{CÁLCULO DO DÉFICIT HABITACIONAL}

A referência básica da Fundação Seade para o cálculo do déficit habitacional no Estado de São Paulo foi a metodologia proposta originalmente pela Fundação João Pinheiro, no âmbito do convênio de assistência técnica para habitação e saneamento, celebrado com o Programa das Nações Unidas para o Desenvolvimento - PNUD, ${ }^{3}$ em 1993, que resultou na publicação, em 1995, do livro Déficit habitacional no Brasil, com estimativas baseadas na Pesquisa Nacional por Amostra de Domicílios - PNAD, de 1990, e no Censo Demográfico, de 1991. Nesse livro, depois de tratar da polêmica questão sobre o sentido habitualmente emprestado ao déficit habitacional, os técnicos da Fundação João Pinheiro lembram que o termo é freqüentemente utilizado com sentidos diferentes, dependendo do autor considerado. Salientam, contudo, que, para o leigo ou leitor menos atento, sua quantificação em um único número é imediatamente associada à interpretação do déficit habitacional como medida da necessidade de construção de novas moradias ou unidades habitacionais. ${ }^{4}$ Em face dessa controvérsia, decidiram agrupar, sob a denominação genérica de necessidades habitacionais, dois tipos de carência definidos conforme as ações exigidas para o seu equacionamento: déficit (que exige construção de moradias) e inadequação (que implica reformas). ${ }^{5}$

O Quadro 1 reproduz, de forma esquemática, a definição operacional do conceito de necessidades habitacionais, tal como concebido pela Fundação João Pinheiro.
Ao redefinir operacionalmente esse conceito, tomando por base as informações levantadas pela PCV, houve preocupação, por parte da Fundação Seade, em não superestimar o déficit habitacional. Assim, quando determinada categoria ou componente englobava variações nas carências detectadas (com possíveis soluções por meio de reformas e/ou melhorias), essas situações foram englobadas na inadequação, e não no déficit, evitando-se que integrassem o contingente de domicílios a serem substituídos (com previsão de novas construções), conforme pode ser visto no Quadro 2.

\section{QUADRO 1}

Procedimentos Adotados pela Fundação João Pinheiro para a Definição Operacional do Conceito de Necessidades Habitacionais

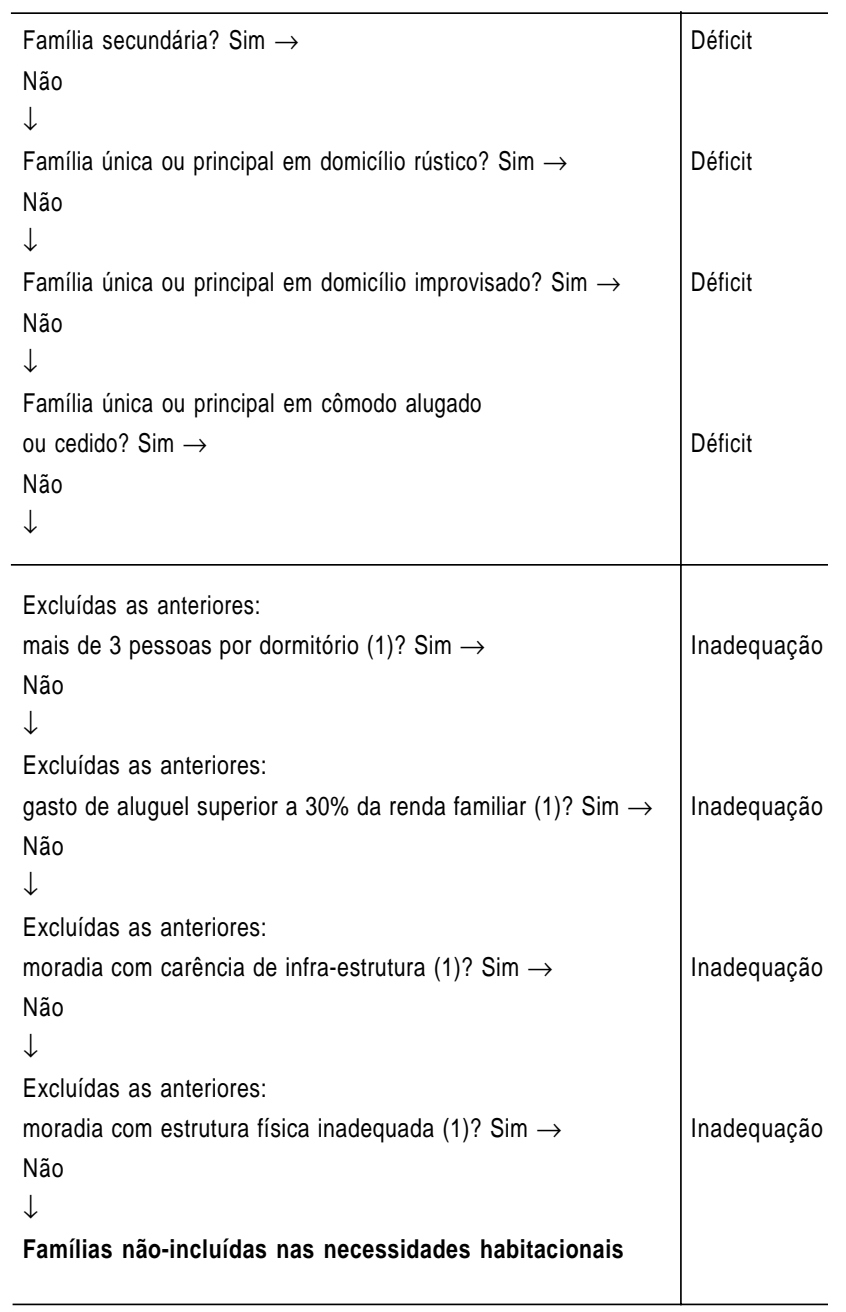

Fonte: Elaboração dos autores.

(1) A classificação depende da renda familiar. 


\begin{tabular}{|c|c|}
\hline $\begin{array}{l}\text { QUADRO 2 } \\
\text { Procedimentos Adotados pela Fundação Seade para a } \\
\text { Operacional do Conceito de Necessidades Habitac }\end{array}$ & QUADRO 2 \\
\hline $\begin{array}{l}\text { Domicílio com mais de uma família? Sim } \rightarrow \\
\text { Não } \\
\downarrow \\
\text { Barraco isolado ou em favela com família única? Sim } \rightarrow \\
\text { Não } \\
\downarrow\end{array}$ & $\begin{array}{l}\text { Déficit } \\
\text { Déficit }\end{array}$ \\
\hline $\begin{array}{l}\text { Casa de alvenaria ou apartamento em favela } \\
\text { com família única? Sim } \rightarrow \\
\text { Não } \\
\downarrow \\
\text { Cortiço com família única? Sim } \rightarrow \\
\text { Não } \\
\downarrow \\
\text { Casa de alvenaria ou apartamento, com família única, } \\
\text { que tem rendimentos de até R } \$ 1.800,00 \text { mensais e paga } \\
\text { aluguel superior a } 30 \% \text { da renda? Sim } \rightarrow \\
\text { Não } \\
\downarrow \\
\text { Casa de alvenaria ou apartamento sem espaço interno } \\
\text { suficiente, com família única? Sim } \rightarrow \\
\text { Não } \\
\downarrow \\
\text { Casa de alvenaria ou apartamento onde o espaço é suficiente } \\
\text { mas há mais de uma pessoa por cômodo e mais de duas } \\
\text { pessoas por quarto e onde sala ou cozinha são usadas para } \\
\text { dormir, com família única? Sim } \rightarrow \\
\text { Não } \\
\downarrow \\
\text { Casa de alvenaria ou apartamento onde falta uma ou } \\
\text { várias ligações com as quatro redes de infra-estrutura urbana, } \\
\text { com família única? Sim } \rightarrow \\
\text { Não } \\
\downarrow\end{array}$ & $\begin{array}{l}\text { Inadequação } \\
\text { Inadequação } \\
\text { Inadequação } \\
\text { Inadequação }\end{array}$ \\
\hline Domicílios não-incluídos nas necessidades habitacionais & \\
\hline
\end{tabular}

Fonte: Elaboração dos autores.

\section{Componentes do Déficit Habitacional}

O déficit habitacional refere-se às moradias que devem ser construídas seja para substituir os domicílios existentes que não apresentam as condições de segurança indispensáveis a seus ocupantes, seja para garantir habitação adequada às famílias que não têm um domicílio de uso privativo.

A Fundação João Pinheiro agrupou, como componentes do déficit habitacional, a coabitação, os domicílios rústicos e os improvisados. Já a Fundação Seade reuniu os barracos e os domicílios que abrigavam mais de uma família. Se a variação, em termos de categorias, é a ausência dos domicílios improvisados no cálculo baseado na PCV, há diferenças conceituais a serem salientadas.
Coabitação Familiar - O primeiro procedimento foi definir a categoria coabitação familiar. Para a Fundação João Pinheiro, ela agrupa as famílias classificadas pelo IBGE como secundárias, ou seja, famílias que residem num mesmo domicílio com outra família, denominada principal. Sua inclusão como componente do déficit habitacional deveuse "à expectativa, em todos os setores da sociedade, de que não é apenas desejável, mas possível e esperado que toda família nuclear possa ter acesso a um lar exclusivo".

Para quantificar as famílias secundárias, os técnicos da Fundação João Pinheiro calcularam a diferença entre o número total de famílias em domicílios particulares e o número de domicílios particulares, obtendo, desta forma, o número de famílias que dividem com outras uma mesma moradia. ${ }^{6}$ A esse grupo somaram, posteriormente, o número de famílias que vivem em cômodos alugados e cedidos, sob a justificativa de que tais famílias também não contam com moradia de uso exclusivo e, assim, demandariam a construção de unidades habitacionais. "Cômodo", aqui, refere-se a um dos tipos de domicílio da Fundação IBGE e corresponde a "domicílio que ocupa um ou mais cômodos de uma casa de cômodos, cortiço, cabeça-de-porco, etc.".

O cálculo da Fundação Seade baseou-se em procedimento diferente do adotado pela Fundação João Pinheiro, pois a premissa segundo a qual a convivência de mais de uma família na mesma moradia impõe a necessidade de uma nova unidade habitacional - um domicílio para cada família - foi considerada discutível, do ponto de vista teórico, uma vez que é possível ocorrer a coabitação voluntária. Assim, a operação visou identificar os domicílios onde havia mais de uma família, não chegando, portanto, ao número de famílias que não têm uma moradia de uso exclusivo (total de famílias secundárias), mas sim ao número de domicílios onde havia coabitação. Com tal procedimento, considera-se o total de domicílios (e não o total de famílias) onde existe coabitação, em vez de adicionar o número de famílias secundárias ao conjunto de moradias estudadas. Assim, supondo que parcela da coabitação é voluntária, evita-se superestimar o déficit e, conseqüentemente, a suposta necessidade de construção de novas unidades habitacionais.?

A Fundação Seade não incluiu os cômodos alugados ou cedidos como integrante do déficit, e o cortiço entrou na inadequação, com justificativa apresentada adiante.

Domicílios Rústicos - Depois da coabitação, a Fundação João Pinheiro identificou os domicílios rústicos, catego- 
ria que reúne, na definição da Fundação IBGE, domicílios permanentes em edificações cuja "construção é predominantemente feita por material improvisado, ou seja, paredes de taipa não-revestida, madeira aproveitada ou material de vasilhame; piso de terra, madeira aproveitada, tijolo de barro cozido ou adobe; cobertura de madeira aproveitada, palha, sapé ou material de vasilhame". Além do desconforto para seus moradores, em decorrência das péssimas condições de salubridade, o domicílio rústico representa risco de contaminação por doenças e risco de desmoronamento - o que justifica a necessidade de ser substituído, mediante construção de unidade habitacional adequada. Como o primeiro componente do déficit reuniu apenas as famílias secundárias, não havia risco de dupla contagem uma vez que foram incluídas nesta categoria apenas as famílias principais que viviam em domicílios rústicos.

No cálculo da Fundação Seade, excluídos os domicílios com mais de uma família (para evitar a dupla contagem, uma vez que pode haver mais de uma família em qualquer tipo de edificação), foram identificados os barracos. Na PCV, o barraco é "moradia construída inteira ou parcialmente com material adaptado, ou seja, não-apropriado a uma habitação. (...) quando o material utilizado na construção da moradia é todo ou em parte adaptado, ou seja, é material reutilizado, de qualquer tipo: alvenaria, madeira, placa, zinco, papelão, plástico, etc., as portas e janelas são aberturas precárias e não há acabamento na casa".

Considerou-se que as famílias moradoras de barraco, isolado ou em favela, demandam a construção de um novo domicílio. As demais moradias de favela (casas de alvenaria ou apartamentos) não entraram como componentes do déficit habitacional, com justificativa apresentada adiante.

Domicílios Improvisados - A Fundação João Pinheiro identificou a categoria de domicílios improvisados, que agrupa, conforme definição da Fundação IBGE, os domicílios "localizados em unidades que não têm dependência destinada exclusivamente à moradia, tais como: loja, sala comercial, etc.". Inclui ainda "prédio em construção, embarcação, carroça, vagão, tenda, barraca, gruta, etc., que estava servindo de moradia" por ocasião do levantamento de campo. Reúne domicílios que, com certeza, devem ser substituídos e só podem ser identificados por uma pesquisa censitária.

O cálculo da Fundação Seade, por se basear em levantamento por amostragem, não considerou os domicílios improvisados.

\section{Componentes da Inadequação Habitacional}

A inadequação habitacional agrupa os domicílios com uma ou mais carências, mas sem a mesma gravidade dos problemas detectados no déficit. Podem, portanto, assegurar condições mínimas de habitabilidade mediante programas alternativos à construção de novas moradias: reformas, ampliações das unidades habitacionais e/ou das redes de abastecimento e coleta de serviços públicos.

A Fundação João Pinheiro reuniu, nessa categoria, os domicílios com adensamento excessivo, com infra-estrutura inadequada ou com elevado comprometimento da renda familiar com aluguel. No cálculo da Fundação Seade, a inadequação habitacional agrupa domicílios congestionados, casas de alvenaria e apartamentos localizados em favelas, cortiços, moradias onde há comprometimento excessivo da renda com aluguel e domicílios com infraestrutura inadequada. Para evitar a dupla contagem, o cálculo de cada componente foi precedido da exclusão dos domicílios identificados no componente anterior, conforme se vê no Quadro 2.

Vale ressaltar que a Fundação Seade utilizou maior número de componentes para identificar a inadequação habitacional. Além disso, há diferenças nos conceitos adotados pelas duas instituições de pesquisa.

Com o intuito de permitir a definição de prioridades das ações públicas na área da habitação, os técnicos da Fundação João Pinheiro adotaram, como procedimento metodológico geral, o tratamento de todos os componentes da inadequação habitacional de forma diferenciada segundo três faixas de rendimento domiciliar: até dois salários mínimos, de dois a cinco salários mínimos e mais de cinco salários mínimos. ${ }^{8}$

Adensamento Excessivo - A identificação dos domicílios com adensamento excessivo pela Fundação João Pinheiro necessitou da definição do limite aceitável de pessoas por domicílio. Para tanto, os autores utilizaram o indicador "moradores por dormitório" e definiram como "congestionado" todo domicílio com presença de mais de três pessoas por dormitório, com a justificativa de que, no Brasil, os domicílios particulares permanentes possuem, em média, de três a quatro moradores. Além de diferenciar a densidade excessiva por classes de renda familiar, separaram os domicílios em duas categorias - casas e apartamentos -, pois é possível estabelecer programas de ampliação para as casas, enquanto os apartamentos congestionados demandam a mudança dos moradores para um domicílio maior. 
No cálculo desse primeiro componente da inadequação habitacional, a Fundação Seade partiu da consideração de que o adensamento excessivo existe quando o espaço não é suficiente para os seus ocupantes e/ou se encontra congestionado. $\mathrm{O}$ cálculo do adensamento excessivo foi feito por dois procedimentos diferentes daqueles adotados pela Fundação João Pinheiro.

O primeiro procedimento implicou a classificação dos domicílios pelo espaço interno disponível. Como já exposto, o indicador da PCV para medir o espaço considera, simultaneamente, o número e os tipos de cômodos, além de identificar o uso (privativo ou coletivo) da cozinha, do banheiro e do tanque de lavar roupas. Assim, para o domicílio ter espaço interno adequado, além de dispor de tanque de lavar roupas de uso exclusivo dos moradores, deve possuir a composição mínima de quarto, sala, cozinha e banheiro. ${ }^{9}$ As moradias onde não há o espaço mínimo indispensável são classificadas como impróprias, porque sua exigüidade exige sobreposição de funções e, aqui, integram a inadequação.

O segundo procedimento (adotado especificamente para o cálculo do déficit habitacional, porque não-incorporado à classificação usual da PCV) foi a identificação, entre os domicílios com espaço interno adequado, daqueles onde há, simultaneamente, mais de uma pessoa por cômodo e mais de duas pessoas por quarto. Assim, é considerada adequada a situação de uma casa com quarto, sala, cozinha e banheiro onde moram um casal e um filho; apesar de haver mais de duas pessoas por quarto, há menos de uma pessoa por cômodo. Da mesma forma, é adequada a condição de um apartamento com quatro quartos, sala, cozinha e banheiro onde vivem oito pessoas; apesar de haver mais de um morador por cômodo, há duas pessoas por dormitório. Os domicílios onde há espaço interno suficiente, mas que foram classificados como congestionados, entram na inadequação.

Nesse componente da inadequação - adensamento excessivo -, a classificação da Fundação Seade apresenta vantagens em relação à da Fundação João Pinheiro. Em primeiro lugar, porque avalia os cômodos disponíveis, comparando-os a um padrão mínimo aceitável. Em segundo lugar, porque identifica, para os domicílios que dispõem desse espaço interno indispensável, situações de congestionamento por um duplo indicador, o que resulta em uma classificação mais apurada. Por fim, porque a Fundação João Pinheiro baseou-se nos dados da PNAD, a qual, como lembraram os próprios autores, define dormitório como "qualquer cômodo que estivesse, em cará- ter permanente, servindo de dormitório para membros do domicílio". Com esse conceito, as famílias em que uma ou mais pessoas dormem regularmente na sala ou na cozinha não foram identificadas como demandantes de ampliações.

Comprometimento Excessivo da Renda com Aluguel - A Fundação João Pinheiro contabilizou, em seguida, os casos de comprometimento excessivo da renda familiar com o aluguel da moradia. Na definição operacional da questão, os técnicos da Fundação João Pinheiro identificaram o comprometimento excessivo quando as famílias despendem mais de $30 \%$ da renda com o aluguel. $\mathrm{O}$ argumento central admitia que, nesses casos, as famílias carentes necessitariam de programa alternativo à construção de novas unidades habitacionais, pois o problema poderia ser resolvido, ao menos em parte, com o estoque de domicílios vagos identificado pela Fundação IBGE.

O limite de $30 \%$ foi adotado por analogia ao procedimento usado pela Caixa Econômica Federal e por outras agências de financiamento habitacional, que consideram essa porcentagem o máximo tolerável de gasto direto com habitação para os mutuários que pagam prestações da casa própria. No entanto, os técnicos da Fundação João Pinheiro ressaltaram a possibilidade de que o índice adotado subestimasse o problema, uma vez que "para as famílias de menor renda mensal - até um salário mínimo, por exemplo - mesmo gastos de $10 \%$ a $30 \%$ podem pesar excessivamente sobre seu orçamento". Apesar dessa ressalva (comprometimento da renda familiar com aluguel ser maior exatamente para as famílias de mais baixa renda), consideram ser esse o limite máximo aceitável no comprometimento da renda, independentemente da faixa de rendimentos. Além de indicar as parcelas mais carentes (até dois salários mínimos e de dois a cinco salários mínimos), fazem distinção entre dois grupos de famílias: as que comprometem de $30 \%$ a $50 \%$ da renda com o aluguel e as que desembolsam mais de $50 \%$.

O cálculo da Fundação Seade sobre comprometimento excessivo da renda com aluguel foi feito de forma diferente. Em vez de identificar os domicílios carentes, foram excluídos da análise o subconjunto formado pe$\operatorname{los} 25 \%$ das famílias de mais alta renda. Quanto à definição do índice máximo de comprometimento da renda familiar com aluguel, foi mantido aquele proposto pela Fundação João Pinheiro, mesmo concordando com a suposição que, para famílias com renda mais baixa (um salário mínimo, por exemplo), a despesa com aluguel em 
porcentagem inferior a $30 \%$ já compromete as demais necessidades básicas.

Casas de Alvenaria e Apartamentos Localizados em Favela - No cálculo da Fundação Seade foram identificados, em seguida, as casas de alvenaria e apartamentos localizados em favela. Não entraram no déficit em razão das grandes variações observadas, atualmente, nos domicílios favelados - tanto pela ocupação do solo quanto pela habitabilidade das moradias -, o que levaria a uma superestimação da necessidade de novas construções. No entanto, pressupõem programas específicos conforme a situação particular de cada favela e de cada moradia; quando uma reforma não é suficiente e as condições exigem a desocupação de toda uma área, com a remoção das famílias, devem integrar o déficit.

Cortiços - Para a Fundação Seade, o componente seguinte foi formado pelos cortiços. Na PCV, esses domicílios não duplicam a contagem com eventuais cortiços em favela pois, neste caso, eles são classificados como moradia em favela. Da mesma forma que para a categoria anterior (casas de alvenaria e apartamentos localizados em favela), os cortiços não entram no déficit devido à variedade de situações encontradas atualmente: há casos em que programas especiais de reforma podem garantir a habitabilidade dos domicílios e outros em que a precariedade das condições exige a desocupação, com a remoção das famílias - estes, sem dúvida alguma, devem fazer parte do déficit.

Infra-Estrutura Urbana Inadequada - A infra-estrutura urbana inadequada também é tratada pela Fundação João Pinheiro de forma diferenciada para as três faixas de renda domiciliar mencionadas. Buscando "levar em conta a real situação econômica dos moradores dos domicílios”, os técnicos da Fundação João Pinheiro definiram, para cada faixa de renda, um padrão mínimo de aceitabilidade dos serviços de infra-estrutura básica (energia elétrica, abastecimento de água, esgotamento sanitário e coleta de lixo), abaixo do qual o domicílio foi considerado inadequado. Mesmo "correndo o risco de sofrer críticas doutrinárias", justificaram tal procedimento com a "suposição de que, dependendo dos setores sociais, maiores ou menores seriam os níveis de exigência dos moradores com os serviços oferecidos". Além da infra-estrutura, classificaram como de estrutura física inadequada os domicílios que não apresentavam instalações sanitárias internas e de uso exclusivo, independentemente da faixa de renda de seus moradores.

A Fundação Seade tratou esse componente da inadequação habitacional - infra-estrutura inadequada - de forma radicalmente diferente. Para a PCV, o padrão de adequação desse componente corresponde ao acesso às quatro redes públicas de abastecimento e de coleta; como única exceção, aceita-se fossa séptica como alternativa à rede de esgoto, pois impede a contaminação do solo.

É fundamental, aqui, uma explicação mais detalhada sobre o tema. A proposta da PCV é considerar a infraestrutura domiciliar urbana ${ }^{10}$ na sua dimensão coletiva ou seja, baseia-se na percepção de que as formas de abastecimento de água e de luz, bem como as alternativas para a coleta do lixo e do esgoto domésticos adotadas nas residências urbanas podem ter conseqüências tanto para a moradia em questão, como para o conjunto de habitações do qual faz parte. ${ }^{11}$ Assim, não é qualquer alternativa às redes públicas que garante a manutenção da saúde coletiva.

A luz elétrica, quando não existe, é substituída por lampião a querosene, velas, etc., que não garantem a segurança dos moradores contra incêndios.

O lixo doméstico, quando não é coletado, favorece a contaminação dos reservatórios de água - particulares (poços) ou coletivos (represas). Quando é jogado em rio, riacho ou represa, a poluição é direta; quando jogado em terreno baldio ou enterrado, a contaminação se dá com as chuvas e com a infiltração do solo até os lençóis de água. Queimar o lixo - alternativa à coleta considerada adequada em alguns estudos baseados em pesquisas domiciliares - também não resolve satisfatoriamente a necessidade de um destino adequado para os dejetos dentro da cidade. ${ }^{12}$

O abastecimento de água, dentro da cidade, feito por bica, nascente ou poço de uso coletivo - sem o controle dos órgãos públicos competentes não tem garantia de salubridade. Quando a água é recolhida de poço individual, os eventuais cuidados da família moradora que o utiliza não são suficientes para garantir que, com a densidade populacional urbana, não haja contaminação subterrânea da água obtida.

Muitos dos destinos alternativos dados ao esgoto doméstico também comprometem a salubridade dos reservatórios de água. Quando ele é jogado a céu aberto a contaminação se dá com as chuvas, que o carregam para os rios ou diretamente para as represas. Quando é uma fossa negra ou rudimentar, a falta de revestimento das paredes 
favorece a contaminação do solo, atingindo os poços das moradias vizinhas e os lençóis d'água que vão desembocar nos reservatórios coletivos. Somente a fossa séptica pode ser considerada uma alternativa adequada à rede pública de esgotamento sanitário pois ela tem as paredes revestidas - isolando os dejetos da possível contaminação subterrânea do solo - e o devido tratamento dos resíduos.

Portanto, em relação ao componente da infra-estrutura urbana, os procedimentos da Fundação Seade foram bem diferentes daqueles adotados pela Fundação João Pinheiro. Nem se chega a discutir a pertinência de diferenciar a inadequação conforme as faixas de renda familiares, uma vez que a consideração da infra-estrutura sob uma perspectiva coletiva elimina a necessidade de diferenciar moradias situadas em áreas urbanas. Pode-se até apontar um argumento contrário a tal procedimento, lembrando que os graus de adensamento habitacional não são homogêneos, mesmo em centros urbanos com mais de 50 mil habitantes, como aqueles investigados pela PCV. No entanto, em razão dos graves problemas que podem ocorrer com a contaminação dos reservatórios de água das cidades, é preferível garantir a devida proteção, mesmo correndo o risco de superestimar a inadequação habitacional.

A avaliação da estrutura física do domicílio, incorporada pela Fundação João Pinheiro neste componente da inadequação habitacional, já havia sido considerada no cálculo da Fundação Seade, quando se procedeu à classificação das moradias conforme o espaço interno.

\section{DIFERENÇAS ENTRE AS METODOLOGIAS}

Como já foi dito, não se trata de comparar a metodologia proposta pela Fundação João Pinheiro com aquela utilizada pela Fundação Seade para ver qual seria a melhor. O que interessa, com o objetivo de aprimorar os procedimentos para a avaliação das necessidades habitacionais, é apontar os avanços obtidos e identificar o que resta empreender. Qualquer que tenha sido o déficit habitacional calculado por ambas, o essencial é reafirmar a importância dos conceitos e procedimentos utilizados. ${ }^{13}$

$\mathrm{Na}$ estimativa da Fundação Seade, os dados da PCV permitiram a identificação de novos componentes para a inadequação, que aprimoram os resultados. Essa identificação mais apurada das carências é fundamental, pois as famílias que não moram em condições consideradas as mais precárias, se não contarem com programas alternativos para garantir condições habitacionais adequadas, po- dem ser compelidas a mudanças de domicílio e, eventualmente, passar a integrar o déficit - com necessidade de construção de casas para substituir as atuais. Portanto, até por uma questão de economia de investimentos públicos, programas alternativos à construção devem ser adotados para as famílias que moram em domicílios inadequados, antes que eles passem a integrar o déficit.

Aqui é preciso lembrar a dificuldade, freqüente entre usuários de informações, de dispor dos dados necessários para os objetivos propostos. No momento da publicação de Déficit habitacional no Brasil, a Fundação João Pinheiro não contava com todos os resultados do Censo Demográfico de 1991. Assim, apesar da vantagem de contar com informações nacionais, com possibilidades de desagregação por Estados e municípios, a análise ficou limitada aos dados disponíveis, bem como aos conceitos adotados pela instituição federal, os quais nem sempre são os mais apropriados para o objetivo proposto. No cálculo feito pela Fundação Seade, por sua vez, houve a vantagem de dispor de informações mais detalhadas sobre as condições habitacionais das famílias entrevistadas. No entanto, como a PCV não é um levantamento específico sobre moradias, deixaram de ser levantadas informações importantes, que possibilitariam uma classificação mais precisa das carências habitacionais.

Não obstante, são fundamentais algumas considerações a respeito da metodologia empregada pela Fundação Seade. A primeira refere-se ao princípio adotado de não superestimar o cálculo do déficit, que implica a construção de moradias. Tal cuidado levou a incluir na categoria de inadequação (e não na do déficit) as casas de alvenaria localizadas em favelas e os cortiços. Como foi dito, essa opção deveu-se à variedade de situações encontradas nesses dois tipos de moradias: como em um e em outro desses conjuntos de domicílios precários não se encontram condições homogêneas de carências existentes, é possível, conforme as particularidades de cada caso, que reformas sejam capazes de garantir condições adequadas de habitabilidade a seus ocupantes. Em uma parcela desses casos será necessário incluir famílias - faveladas ou encortiçadas - no cálculo do déficit, pela impossibilidade de reformas nas suas moradias atuais. No entanto, supõe-se que tal necessidade só será definida após se buscar uma solução alternativa, antes de se optar pela construção de novas moradias. Sendo assim, os dois tipos de moradias precárias permanecem no item de inadequação habitacional.

Outra consideração sobre a metodologia adotada pela Fundação Seade diz respeito à renda familiar. De acordo 
com a premissa teórica básica da PCV, de que a pobreza não se resume à falta de renda, foi evitada a diferenciação das necessidades habitacionais a partir dos rendimentos familiares. ${ }^{14}$ Além da dificuldade em se estabelecer um corte para separar famílias mais ou menos carentes (é extremamente difícil arbitrar a faixa de renda a partir da qual as famílias têm, de fato, condições de escolha para morar com uma determinada limitação), parece mais oportuno, na classificação das necessidades habitacionais, ater-se a indicadores relacionados diretamente à moradia. Os domicílios classificados na inadequação habitacional devem, como no caso dos cortiços e das moradias em favelas, passar por uma avaliação que permita definir prioridades, eventualmente incluindo corte por renda.

A introdução de componentes na classificação da inadequação habitacional, feita pela Fundação Seade, torna seu cálculo mais preciso. Com efeito, a Fundação João Pinheiro utilizou a fonte de dados disponível mais completa para a análise da situação nacional. Se, por um lado, essa alternativa permitiu estudar as regiões e os Estados e comparar os resultados obtidos nas diferentes áreas, por outro, a escolha dos indicadores e as conclusões foram determinadas pelos procedimentos adotados pela Fundação IBGE, que implica limitações. É o caso da definição de um padrão mínimo de adequação habitacional: se é preciso conhecer as condições habitacionais a fim de informar as políticas públicas e possibilitar o tratamento diferenciado conforme as carências encontradas, faz-se necessário estudar o conjunto de moradias, relacionandoas a um padrão mínimo de adequação. Ou seja, não se trata unicamente de identificar os domicílios precários, mas partir de um padrão mínimo e classificar todas as habitações. A Fundação Seade pôde incluir componentes - domicílio construído em alvenaria e localizado em favela, cortiço, triplo indicador para medir densidade e espaço interno - que a Fundação João Pinheiro não dispunha.

Alguns conceitos utilizados pela Fundação João Pinheiro não correspondem aos adotados pela $\mathrm{PCV}$; nesses casos, quando a proposta da Fundação João Pinheiro não era contrária à da PCV aplicaram-se os conceitos da Fundação João Pinheiro, eventualmente com adaptações consideradas indispensáveis; foi o caso, por exemplo, de levar em conta a coabitação como componente do déficit (pressupondo construção de novas moradias) e diminuir o risco de superestimação considerando domicílios com mais de uma família. Quando a proposta da Fundação João Pinheiro mostrou-se inviável, pela concepção PCV, ela foi modificada; por exemplo: considerar infra-estrutura conforme faixa de renda familiar se contrapõe à concepção da PCV, uma vez que a abordagem coletiva não permite diferenciações, devido aos riscos de contaminação que acarreta para o conjunto da população.

Registre-se, ainda, que, nas duas metodologias, é preciso incluir os procedimentos para evitar a dupla contagem. Quando se pretende quantificar o total de moradias a serem construídas e, por outro lado, o total de domicílios que necessitam de reformas ou outros programas alternativos à construção, tais procedimentos são fundamentais para não se obter uma superestimação das carências, uma vez que é possível encontrar várias carências em um mesmo domicílio. Quando, no entanto, busca-se implantar programas específicos, cada componente deverá ser considerado isoladamente.

\section{CONSIDERAÇÕES FINAIS}

Ao publicar o livro Déficit habitacional no Brasil, em 1995, a Fundação João Pinheiro deu um passo decisivo para o aprimoramento dos estudos e pesquisas sobre carência habitacional no país. Além dos resultados em forma de estimativas - que são uma referência objetiva para o planejamento de ações públicas no setor -, a grande contribuição do estudo é a explicitação dos conceitos e procedimentos adotados para a mensuração do déficit habitacional.

A análise desses conceitos e procedimentos, sobretudo de suas justificativas teóricas e definições operacionais, é fundamental para a avaliação do potencial e das limitações dos estudos sobre habitação que se baseiam nos levantamentos domiciliares de abrangência nacional realizados periodicamente pela Fundação IBGE, como o Censo Demográfico e a Pesquisa Nacional por Amostra de Domicílios - PNAD. A busca de aprimoramento na definição de conceitos e indicadores e, portanto, de informações a serem coletadas, deve ser empreendida pelos vários setores e técnicos que se dedicam ao estudo das condições habitacionais ou que trabalham com as parcelas mais carentes da população, para garantir que os dados colhidos possam, de fato, subsidiar o planejamento das ações governamentais.

Alguns conceitos inovadores foram introduzidos pela Fundação Seade a partir do primeiro levantamento da PCV, em 1990. Para tipos de edificação foi acrescentada, no levantamento de 1994, uma subclassificação aos tipos tradicionalmente adotados - barraco isolado, moradia em favela, cortiço, apartamento e casa de alvenaria. Essa úl- 
tima categoria foi subdividida em casa isolada (única no lote) e casa frente-fundos (quando a casa divide com um ou mais domicílios o terreno onde está construída). Esse procedimento foi adotado devido ao grande número de moradias classificadas como casa (cerca de $80 \%$ ), categoria que agrupa uma grande variedade de domicílios quanto a padrão arquitetônico, condições de conservação e salubridade, etc., e na hipótese de que uma família que deve compartilhar com outra(s) o lote onde mora - mesmo se os equipamentos hidráulicos são de uso privativo a cada uma delas, garantindo cozinha e banheiro de uso exclusivo - se submete a limitações de privacidade que envolvem condições de vida menos adequadas do que teria se vivesse em casa isolada.

É, ainda, o caso da avaliação do estado de conservação do imóvel, que determina as condições de salubridade em que vivem as famílias ocupantes. Mesmo apartamentos e casas de alvenaria aparentemente confortáveis, com inúmeros cômodos e sem congestionamento não oferecerão condições habitacionais adequadas se forem malconstruídos ou mal-conservados - com problemas de ventilação, iluminação, umidade, etc., que prejudicam a saúde dos moradores. A PCV introduziu, no levantamento de 1994, questões para determinar o grau de conservação e salubridade dos imóveis. No entanto, falta elaborar indicadores objetivos mais completos, para que esse levantamento não se proceda unicamente com base nas respostas dos entrevistados, como foi feito, até o momento, pela PCV.

A busca de aprimoramento nos indicadores de carência habitacional deve incluir a identificação dos domicílios tanto nas suas características de construção e de espaço, como nas formas de ocupação desse espaço, lembrando, como já foi feito anteriormente, que as várias modalidades de carência habitacional são difíceis de ser identificadas, quando se trata da cidade real e não da $l e-$ $\mathrm{gal}$. As inúmeras carências a serem identificadas incluem os domicílios localizados em áreas vizinhas a fontes de risco (como gasodutos, linhas de alta tensão, encostas, etc.) ou a reservatórios coletivos de água que não garantem segurança aos moradores; as situações de contratos verbais de locação, onde o proprietário define o valor do aluguel sem o controle legal e o locatário não reclama temendo perder sua moradia; as ocupações ilegais de habitações inacabadas, dos chamados "invasores", morando em permanente risco de acidentes (desabamentos, incêndios, etc.), uma vez que os imóveis não têm a supervisão técnica devida e indispensável; as ocupações de terrenos, por "invasores" que constroem suas casas em áreas nem sempre seguras (próximas a encostas ou represas, por exemplo), situações que, muitas vezes, só se tornam conhecidas quando ocorrem acidentes sérios. E tantas outras situações camufladas, que devem ser conhecidas para avaliar as condições habitacionais da população mais carente.

Devem ser lembradas, por último, duas carências de informações ligadas a limitações de qualquer pesquisa amostral. Uma delas refere-se aos chamados "moradores de rua" que, obviamente, são uma parcela a integrar o déficit habitacional. Outra limitação é a falta de espacialização das informações dentro da malha urbana pois, em cidades, as condições habitacionais são distintas conforme o distrito e o bairro em que se localizam.

Vale a pena chamar a atenção para uma característica setorial, já referida anteriormente: os estudos sobre condições habitacionais geralmente identificam as moradias mais precárias de um lado, contrapostas às demais, ou aprofundam o conhecimento de um determinado tipo de carência. Mesmo prestando informações importantes, esse tipo de abordagem não permite ações diferenciadas dos órgãos públicos, pois não possibilita estabelecer prioridades. E, tratando-se de moradias, os recursos a serem investidos supõem altos investimentos - se a solução proposta é a construção de unidades habitacionais para a população mais carente. Assim, as informações serão mais eficazes se diferenciarem a necessidade de construção de programas alternativos a ela.

Foi exatamente a partir dessa premissa que a Fundação Seade, ao calcular as necessidades habitacionais, cuidou para não superestimar o déficit, mesmo com a eventual superestimativa da parcela de moradias inadequadas. Esse procedimento supõe programas imediatos para sanar as carências dos domicílios classificados como inadequados pois, como já foi dito, as moradias que não se encontram em condições mais precárias, mas não dispõem das condições mínimas de habitabilidade abrigam famílias que, se não tiverem acesso a melhorias nos seus domicílios, correm o risco de ver se deteriorar suas condições e passarem a compor o agrupamento das moradias mais precárias, saindo da inadequação para o contingente do déficit.

Em suma, é de extrema importância incentivar os órgãos especializados na área de habitação e os técnicos que trabalham com moradia para buscarem aprofundar a definição dos indicadores que traduzam as diferenças a serem observadas e a conseqüente classificação mais apurada das 
carências existentes. Estaremos, assim, todos - quem busca conhecer a realidade e quem atua para modificá-la - trabalhando na mesma direção, de melhorar as condições de moradia e de vida da população mais carente.

\section{NOTAS}

E-mail dos autores: mlbpgene@seade.gov.br e ovcosta@seade.gov.br

1. A Fundação João Pinheiro é o órgão oficial do Governo do Estado de Minas Gerais, responsável pela articulação do sistema estadual de estatística, que produz e divulga estatísticas e indicadores econômico-financeiros, demográficos, sociais, etc. Volta-se também para a realização de projetos de pesquisa aplicada, consultorias, desenvolvimento de recursos humanos e ações de apoio técnico ao sistema estadual de planejamento e demais sistemas operacionais do Governo do Estado de Minas Gerais, nas áreas da administração, economia, estudos históricos, culturais, sociais e políticos. Para mais informações, consultar o portal da Fundação João Pinheiro na internet (www.fjp.gov.br).

2. Em exercícios realizados com os dados da PCV, constatou-se que são sobretudo as moradias classificadas como adequadas as que dispõem de cômodos destinados a outras atividades, além das quatro essenciais (complementares às tarefas domésticas - área de serviço, por exemplo - ou destinadas a atividades lucrativas - consultório, por exemplo), o que valida o indicador que totaliza os cômodos destinados às quatro funções básicas.

3. Projeto PNUD - Sepurb/BRA/93/013 Assistência Técnica para Habitação e Saneamento.

4. Para salientar a complexidade que envolve a discussão sobre déficit habitacional no Brasil, os técnicos da Fundação João Pinheiro alertam: "Nos últimos anos, dependendo dos métodos e parâmetros utilizados, as estimativas variaram de 6,5 a 15,4 milhões de unidades, o que na prática, gera a difusão de números míticos, de 10 a 12 milhões repetidos pelas autoridades, estudiosos e empresários ligados ao setor imobiliário".

5. Segundo os autores, as necessidades habitacionais englobam "o déficit habitacional e a inadequação de moradias em determinado momento no tempo, ou seja, problemas sociais de toda ordem direta ou indiretamente relacionados à habitação". Para garantir o sentido da terminologia empregada, a Fundação João Pinheiro lembra que demanda demográfica "não é déficit habitacional. Apenas dimensiona quantas moradias adicionais devem ser acrescentadas ao estoque para acomodar condignamente o crescimento populacional em determinado intervalo de tempo. Não se preocupa nem deve se preocupar com nenhum aspecto social prévio ou considerações sobre a qualidade das moradias ou sua inadequação, que transcendem sua competência técnica de elaboração de números".

6. Importa salientar que, com tal procedimento, a parcela de famílias secundárias foi acrescentada ao total de domicílios - o que exige cuidado na aplicação da metodologia proposta, pois muitos dados referem-se ao número de domićílios e não de famílias.

7. Vale notar que, de acordo com a PCV, na RMSP, os domicílios com mais de uma família correspondem a cerca de $2,5 \%$ e, nestes, a grande maioria abriga apenas uma família secundária.

8. Apesar de introduzir, como procedimento metodológico, a diferenciação conforme a renda familiar, os técnicos da Fundação João Pinheiro julgaram aconselhável não estimar cada componente das necessidades habitacionais com tal diferenciação pois, no caso do déficit, a situação implica necessariamente novas moradias (independentemente dos rendimentos) e, no caso da inadequação, porque esse procedimento implicaria projetar a distribuição de renda domiciliar detectada em 1991 para 1995, o que foi considerado temerário.

9. As famílias com mais alta renda que podem, em tese, escolher morar em um domicílio que tenha condições de habitabilidade adequadas, apesar de conter apenas três cômodos (por exemplo, sala/quarto, mais cozinha, mais banheiro), são relativamente pouco numerosas: em 1994, de acordo com a PCV, as famílias com renda total superior a 20 salários mínimos e, simultaneamente, com renda per capita superior a seis salários mínimos coorrespondiam a 4,4\% na RMSP.

10. Em Déficit habitacional no Brasil, a Fundação João Pinheiro privilegia a análise das necessidades habitacionais urbanas, "pois nas cidades concentram-se atualmente mais de $75 \%$ da população do país, onde são maiores os problemas do habitat". Quanto à PCV, o levantamento de 1998 incluiu os municípios paulistas com população urbana superior a 50 mil habitantes.
11. Devido à impossibilidade de espacialização, dentro da cidade, dos dados na PCV (o que representa sério limite para o aprofundamento da análise sobre as alternativas às redes públicas de infra-estrutura urbana), algumas premissas foram adotadas para o estudo sobre a infra-estrutura urbana:

- como o levantamento da PCV abrange centros urbanos com mais de 50 mil habitantes, considera-se o grau de adensamento habitacional homogêneo e suficientemente alto para que certas alternativas às redes públicas interfiram nos domicílios vizinhos - somente a fossa séptica foi considerada alternativa adequada à rede de esgoto, pois garante a devida proteção contra a contaminação dos reservatórios de água;

- quanto ao solo, considera-se, em vista da alta densidade habitacional referida na premissa anterior, que é permeável a ponto de possibilitar a contaminação dos reservatórios de água (individuais e coletivos) pela infiltração de dejetos ou lixo, e homogêneo nessa permeabilidade;

- consideram-se verdadeiras as informações obtidas dos próprios moradores, mesmo levando em conta que, eventualmente, não correspondem à realidade; é o caso, por exemplo, do locatário que acredita que sua casa tem ligação com a rede de esgoto, quando, na verdade, a canalização subterrânea termina em um córrego.

12. Cabe uma explicação mais detalhada sobre esta alternativa. Entre as diferentes substâncias que compõem o lixo, somente as orgânicas, que são putrefativas, provocam mau cheiro e favorecem a proliferação de animais indesejáveis (moscas, mosquitos, baratas, ratos), responsáveis pela transmissão de várias doenças ao homem. Os moradores de centros urbanos que habitualmente queimam o lixo doméstico, nem sempre conhecem as implicações da queima de detritos. Buscam, de imediato, eliminar o mau cheiro e a presença de bichos. No entanto, mesmo quando alcançam esse objetivo (ou seja, não deixar resíduos que continuem infestando o ar e alimentando insetos), as demais substâncias muitas vezes permanecem acumuladas. São materiais combustíveis (panos, papéis, couros, plásticos, madeiras, etc.) ou incombustíveis (metais, vidros, pedras, etc.) que mantêm o amontoado de detritos queimando durante longo tempo (poluindo o ar, muitas vezes com a emissão de gases tóxicos) ou se deterioram, espalhando substâncias nocivas à saúde. É o caso, por exemplo, das pilhas que, quando se rompem, deixam vazar os metais que as compõem; com as chuvas esses metais atingem rios e riachos ou se infiltram no solo. Se as pilhas são de dimensões reduzidas e não estão diariamente no lixo doméstico, com outros materiais também ocorre o mesmo processo e, em centros urbanos, o acúmulo de ocorrências transforma casos isolados em problema coletivo. Assim, somente o serviço de coleta regular - feita diretamente por caminhões ou por caçamba (recipiente apropriado para o recolhimento do lixo, esvaziado periodicamente) - é considerado adequado para a garantia da saúde pública.

13. Apenas como ilustração, o déficit habitacional na Região Metropolitana de São Paulo, tal como calculado pela Fundação João Pinheiro, a partir de projeções baseadas nos dados do Censo Demográfico de 1991, foi de cerca de 9,5\%. Para a Fundação Seade, tomando por base os dados da PCV-1998, a estimativa foi de $7,7 \%$.

Quanto à inadequação habitacional, a estimativa da Fundação Seade agrupa 41,9\% das moradias e a Fundação João Pinheiro não apresentou parcela única neste componente das necessidades habitacionais (por não dispor, naquele momento, dos dados indispensáveis a este cálculo).

14. A PCV partiu da hipótese que a pobreza não deve ser medida com um único indicador, por mais sensível que seja, e elaborou uma metodologia que classifica as famílias por várias características socioeconômicas. Foram criadas quatro escalas setoriais - moradia, instrução, emprego e renda -, a partir da definição do padrão mínimo de adequação e da hierarquização dos atributos indispensáveis ao setor. Cada setor pode ser abordado em sua escala mais completa, com as várias categorias hierárquicas, ou em sua escala dicotômica, que divide as famílias em carentes e não-carentes, dependendo de sua posição com relação ao padrão mínimo de adequação. A classificação simultânea dos quatro setores, por meio de suas escalas resumidas, permite a ordenação e o agrupamento das famílias conforme seu perfil socioeconômico.

\section{REFERÊNCIAS BIBLIOGRÁFICAS}

BRANCO, P.P.M. et alii. "Habitação popular: metas para a década de 90". In: Fundap. Questão social. Políticas sociais no Brasil. Avaliação e propostas para os anos 90. São Paulo, Documento de Trabalho/QS1, mar. 1991.

CHOMBART DE LAUWE, P. et alii. Famille et habitation. Sciences humaines et conceptions de l'habitation. Travaux du Groupe d'Ethnologie Sociale. Paris, Centre National de la Recherche Scientifique (CNRS), 1959. 
CDHU. Planejamento do dimensionamento dos cortiços no Município de São Paulo: plano de pesquisa para estudo de caso sobre as relações entre a população encortiçada, os proprietários e os intermediários. São Paulo, Diretoria Técnica/Superintendência de Planejamento e Desenvolvimento Tecnológico, abr. 1988, 33 p.

EMPLASA. Sumário de dados da Grande São Paulo. São Paulo, 1995.

FUNDAC̄̃̃O JOÃO PINHEIRO. Déficit habitacional no Brasil. Belo Horizonte, Projeto PNUD-Sepurb/BRA/93/013, 1995.

JARDIM, N.S. (coord.) et alii. Lixo municipal. Manual de gerenciamento integrado. $1^{a}$ ed. São Paulo, IPT/Cempre (Compromisso empresarial para reciclagem), 1995 (Publicação IPT, 2.163).

MINISTÉRIO DO INTERIOR. Necessidades habitacionais para o periodo 19901995. Brasília, 1989.

PASTERNAK TASCHNER, S. Espaço e população. Dissertação de Mestrado. São Paulo, 1975, mimeo.

Moradia e pobreza: Habitação sem saúde. Tese de Doutorado. São Paulo, Faculdade de Saúde Pública da USP, 1982, mimeo.

SANTOS, M. Metrópole corporativa fragmentada: o caso de São Paulo. São Paulo, Nobel/Secretaria de Estado da Cultura, 1990.
SÃO PAULO (Cidade). PMSP. Habitação. Plano urbanístico básico de São Paulo (PUB). São Paulo, v.3, 1969.

SÃO PAULO (Cidade). PMSP/Sedes/Assessoria Coordenadora de Planejamento Setorial Unidade de Pesquisa. Indicadores de habitação e serviços urbanos. São Paulo, Sebes, 1973 (Indicadores Sociais, 2).

SÃO PAULO (Estado). Secretaria de Estado dos Negócios da Economia e Planejamento. Grupo Executivo da Grande São Paulo. Plano metropolitano de desenvolvimento integrado (PMDI). São Paulo, Gegran, 1971.

VERAS, M.P.B. e TASCHNER, S.P. "Evolução e mudanças nas favelas paulistanas". Espaço e Debates. São Paulo, v.10, n.31, 1990 (Revista de Estudos Regionais e Urbanos).

VETTER, D.M. "Problemas conceituais e operacionais na avaliação da 'adequação' das condições residenciais através de indicadores elaborados com dados dos censos e das PNADs." Revista Brasileira de Estatística. Rio de Janeiro, v.42, n.168, out./dez. 1981, p.283-314.

UNICAMP/FECAMP. Situação da pobreza no Brasil: Principais causas e alternativas de políticas corretivas. Campinas, Convênio Fecamp/Unicamp (termo aditivo 02), jun. 1989 